\title{
RETROPERITONEOSCOPIC SURGERY WITH EXTRACORPOREAL URETERO-URETERAL ANASTOMOSIS FOR TREATING RETROCAVAL URETER
}

\author{
M. TOBIAS-MACHADO, MARCO T. LASMAR, ERIC R. WROCLAWSKI \\ Department of Urology, ABC Medical School, Santo André, Sao Paulo, Brazil
}

\begin{abstract}
We present a case of retrocaval ureter featuring laparoscopic technique treatment using extraperitoneal access and extracorporeal suture of the ureteral stumps. Surgical time was $130 \mathrm{~min}$ utes, and the anastomosis was performed in 40 minutes. There were no intra- or postoperative complications, and the patient was discharged from hospital on the second postoperative day. The mediumterm outcome featured similar results to pure laparoscopic technique.

We conclude that this technical variation for treatment of retrocaval ureter makes the procedure easier and provides a drastic reduction in surgical time, without compromising the minimally invasive aspect of this kind of approach.
\end{abstract}

Key words: ureter; urogenital abnormalities; vena cava, inferior; laparoscopy

Int Braz J Urol. 2005; 31: 147-50

\section{INTRODUCTION}

Retrocaval ureter is a rare congenital entity that ultimately results in a developmental abnormality of the vena cava inferior, located postero-laterally to the ureter.

Though it is a congenital pathology, symptoms usually arise during the 3rd or 4th decade of life and result from the compressive effect exerted by the vena cava on the ureter with consequent proximal uretero-hydronephrosis. Diagnosis can be suggested through excretory urography and confirmed through helical computerized tomography.

The treatment is surgical and is always suggested in symptomatic cases and/or when signs of renal obstruction are verified. Currently, laparoscopic surgery has been employed as the minimally invasive therapeutic option. Our objective was to present a new technical approach that uses laparoscopic surgery with extraperitoneal suture as a strategy for reducing surgical time.

\section{CASE REPORT - SURGICAL TECHNIQUE}

A 24-year old woman complained on recurring lumbar colic pain associated with repeated episodes of acute pyelonephritis on the same side. Laboratory tests showed preserved renal function.

The ultrasound revealed moderate dilation of the pyelocaliceal system in the right kidney. The excretory urography showed a J-shaped proximal ureter, suggesting retrocaval ureter (Figure-1). Helical tomography confirmed this diagnosis.

Due to the clinical picture and findings of complimentary tests, we decided for surgical treatment. We used the standard extraperitoneal laparoscopic access through 3 ports (Figure-2).

We dissected the entire proximal ureter and released the lower renal pole, and then dissected the distal ureter up to the point of maximum visualization in the interaortocaval position, while preserving the periureteral fat. The ureter was identified and brought to the extremity of the trocar positioned at 


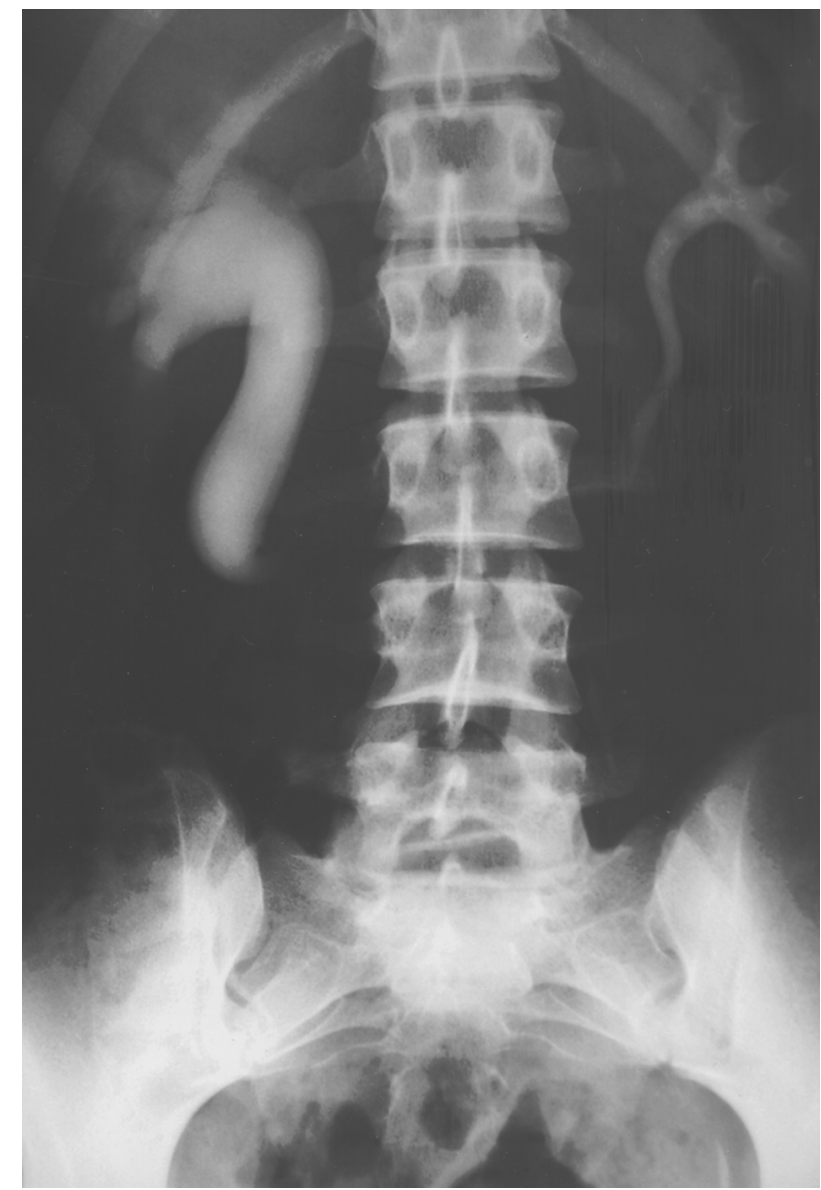

Figure 1 - Excretory urography showing proximal uretero-hydronephrosis and typical "J" configuration of retrocaval ureter.

the extremity of the 12th rib, while observing which would be the point with the least tension for exteriorization. The ureter was sectioned at this site. The ureteral stumps were exteriorized through the incision of the 12-mm port after enlarging the skin incision to $20 \mathrm{~mm}$. The proximal and distal ureteral margins were resected and a good vascularization was observed. We performed a continuous spatulate suture on the posterior aspect of the ureter using monocryl 4-0. A double-J catheter was then inserted. The anterior ureter was sutured like the posterior aspect. The ureter was repositioned at its usual location (Figure-3) and a Penrose was inserted for drainage. Total surgical time was 130 minutes, 40 minutes of which were employed for the anastomosis. Estimated bleeding was $50 \mathrm{~mL}$ and there were no intraoperative complications. The patient was discharged from hospital on the 2 nd postoperative day with no intercurrence. The double-J catheter was maintained for 6 weeks, and the patient remained asymptomatic following removal. A control urography performed 3 months after surgery showed good drainage of the ureter with correction of the anatomic abnormality (Figure-4).

\section{COMMENTS}

The classical treatment for retrocaval ureter consists of separating the ureter, re-anastomosing its stumps and replacing the ureter in its usual position while maintaining its irrigation.

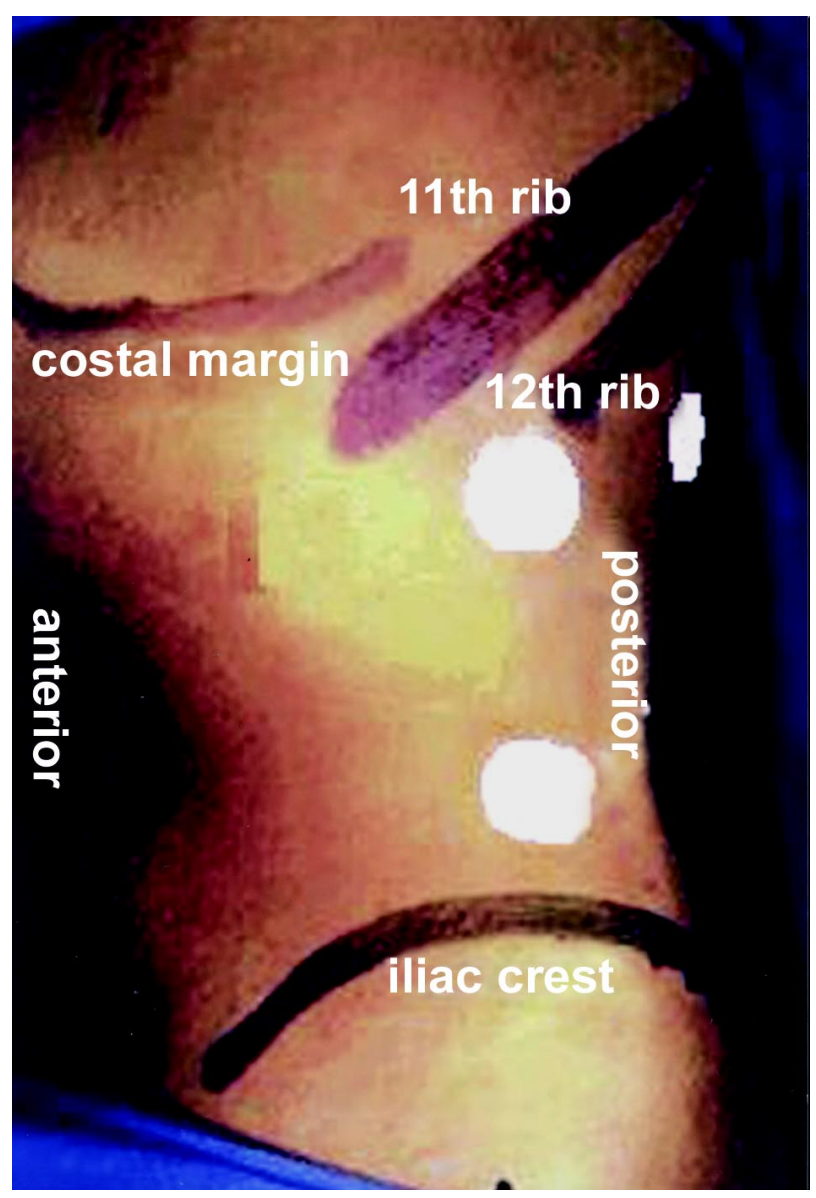

Figure 2 - Configuration of ports used during surgery. A first 12-mm port located between the extremities of the 11th and 12th ribs (where the ureteral stumps were exteriorized), a second 10mm port located $2 \mathrm{~cm}$ from the iliac spine (for the 0 grade optic) and a third $5-\mathrm{mm}$ port located $1.5 \mathrm{~cm}$ from the costovertebral angle's bisector. 


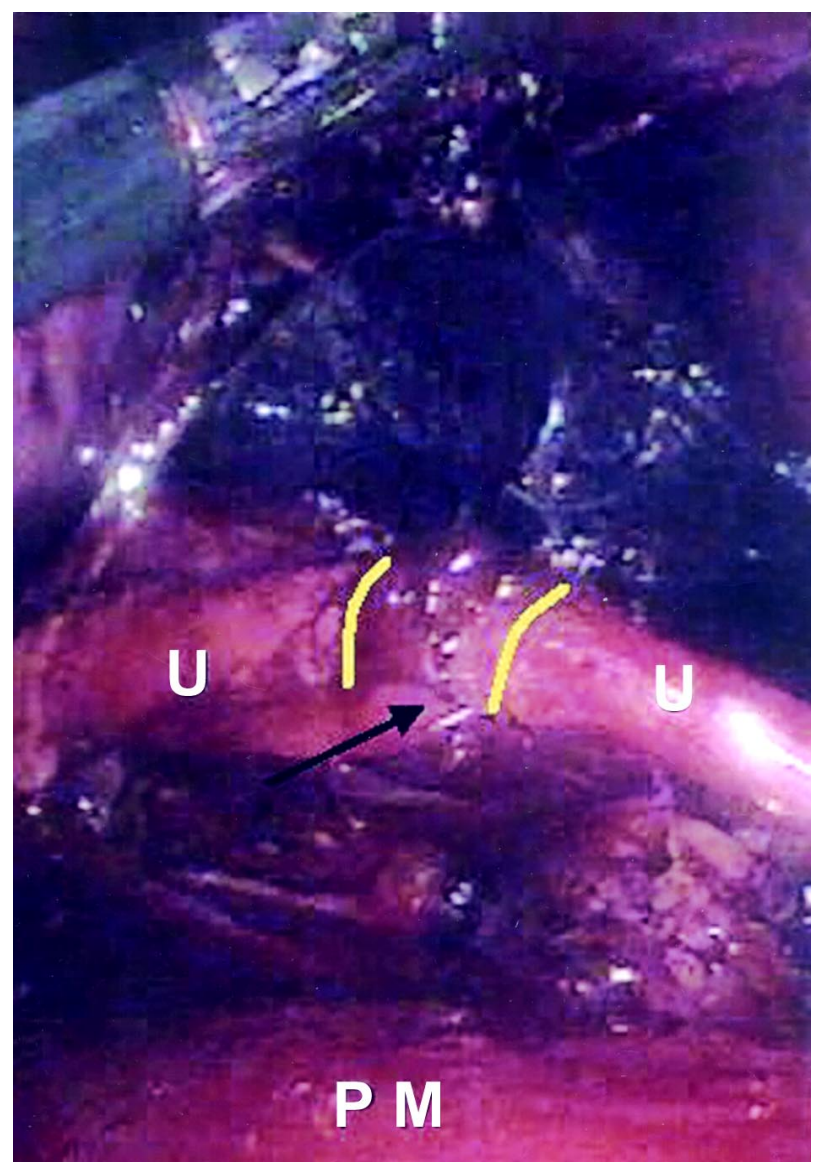

Figure 3 - Retroperitoneoscopic aspect of the re-anastomosed ureter (between yellow lines) ( $U$ - ureter; $P M$ - psoas muscle).

The transperitoneal laparoscopic surgical repair for retrocaval ureter was first described by Baba et al. in 1994 (1). Comparisons between previous work using a laparoscopic approach and historical reports on open surgery for treatment of retrocaval have shown the advantages of minimally invasive access, specifically a shorter hospital stay, reduced postoperative pain, early return to daily activities and a remarkably superior esthetic effect while maintaining efficacy $(2,3)$.

The main limiting factor for laparoscopic treatment of this pathology has been the intracorporeal anastomosis of the ureter, which considerably increases surgical time (1-3), Table-1.

The majority of reports have used a transperitoneal access. In 1999, Salomon et al. described the feasibility of the surgical repair of retro- caval ureter through laparoscopic access using the retroperitoneal approach (3).

We are presenting here a technique that offers a feasible, efficacious and fast alternative for cases where it is possible to exteriorize the stumps that will be anastomosed. Difficulties resulting from the intracorporeal suture, which is more significant when the extraperitoneal access is preferred, are thus eliminated. Antegrade insertion of the double-J catheter prevents the endoscopic approach from being performed at the beginning. The patient's body habitus is important in order to safely accomplish this approach. The proper planning of the site where the ureter should be sectioned, the perfect maintenance of its irrigation properties and a proper assessment of the ureteral segment's feasibility are fundamental for

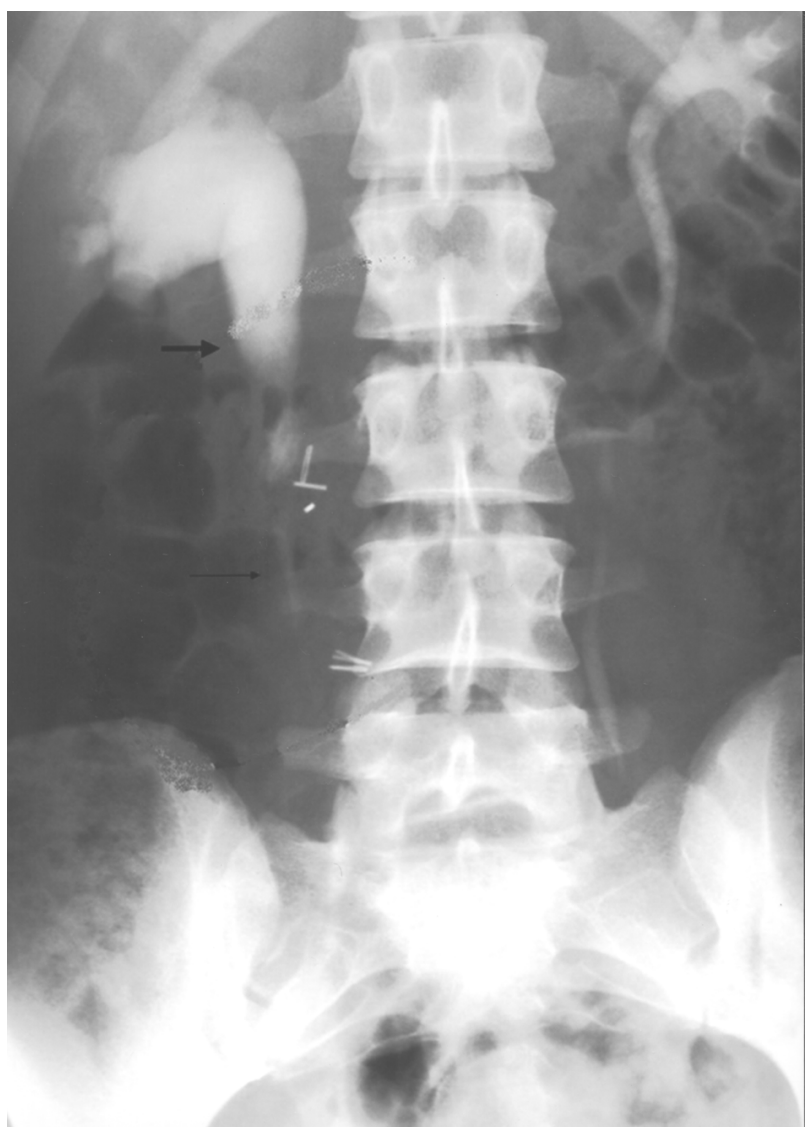

Figure 4 - Excretory urography performed after reconstruction showing good drainage of the ureter (thick arrow = pre-anastomosis; thin arrow = post-anastomosis). 
Table 1 - Case reports in the literature using laparoscopic technique for surgical repair of retrocaval ureter.

\begin{tabular}{|c|c|c|c|c|c|}
\hline Author & N. of Cases & Access & Ports & Surgical Time & Anastomosis Time \\
\hline Baba, 1994 & 1 & Transperitoneal & 5 & $9 \mathrm{~h} 20 \mathrm{~m}$ & $2 \mathrm{~h} 30 \mathrm{~m}$ \\
\hline Matsuda, 1996 & 1 & Transperitoneal & 5 & $7 \mathrm{~h} 30 \mathrm{~m}$ & - \\
\hline Polascik, 1998 & 1 & Transperitoneal & 3 & $3 \mathrm{~h} 45 \mathrm{~m}$ & - \\
\hline Salomon, 1999 & 1 & Retroperitoneal & 4 & 4h $30 \mathrm{~m}$ & - \\
\hline \multirow[t]{2}{*}{ Ameda, 2001} & 2 & Transperitoneal & 4 & $7 \mathrm{~h} 30 \mathrm{~m}$ & - \\
\hline & & Retroperitoneal & 4 & $6 \mathrm{~h} 40 \mathrm{~m}$ & - \\
\hline Present study, 2004 & 1 & Retroperitoneal & 3 & $2 \mathrm{~h} 10 \mathrm{~m}$ & $40 \mathrm{~m}$ \\
\hline
\end{tabular}

success using this technical variation. The long-term postoperative result shows an effectiveness that is similar to the pure laparoscopic technique. Surgical time was the lowest posted in the literature so far.

The authors acknowledge Dr. Pedro Forseto Jr. and Dr. Marcelo M. Gava for patient assistance and cooperation in the conduction of this project.

\section{REFERENCES}

1. Baba S, Oya M, Miyahara M, Deguchi N, Tazaki H: Laparoscopic surgical correction of circumcaval ureter. Urology. 1994; 44: 122-6.

2. Matsuda T, Yasumoto R, Tsujino T: Laparoscopic treatment of a retrocaval ureter. Eur Urol. 1996; 29: 115-8.

3. Salomon L, Hoznek A, Balian C, Gasman D, Chopin DK, Abbou CC: Retroperitoneal laparoscopy of a retrocaval ureter. BJU Int. 1999; 84: 181-2.

Received: September 17, 2004 Accepted after revision: February 4, 2005

Correspondence address:

Dr. Marcos Tobias-Machado

Rua Graúna, 104 / 131

São Paulo, 04514-000, SP, Brazil

Phone: + 5511 288-1003

E-mail: tobias-machado@uol.com.br 